\title{
The Elasticity Of Marketing Return On Investment
}

Theodore Mitchell, University of Nevada, USA Howard Olsen, University of Nevada, USA

\begin{abstract}
This paper demonstrates that the marketing return on investment (MROI) can be inversely related to profits in healthy, high performance firms. In light of this, the authors contend that MROI is a poor metric for evaluating profitable performance, because lower MROI is not always a sign of poor performance and higher MROI is not always a sign of higher performance. However, MROI can be converted into an elasticity of efficiency and used as a diagnostic tool to help marketing managers choose more profitable levels of promotion. MROI in the role of a diagnostic tool has stronger theoretical foundations than in its role as an evaluation metric. The paper presents the elasticity of MROI to changes in marketing expense as a practical tool for marketing managers to improve the profitability of marketing.
\end{abstract}

Keywords: Marketing Return on Investment; Economics; Finance; ROI; MROI; Elasticity

\section{INTRODUCTION}

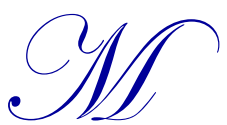

arketing managers need metrics to evaluate performance and to indicate directions for improved profitability in the future. Marketing metrics fall on a continuum from being purely diagnostic at one end to being purely evaluative at the other end. For example, profits and return on assets are metrics that are used primarily for evaluating performance. Larger profits and a higher ROA are always measures of more desirable performance. However, there are relatively few metrics that are purely evaluative. That is to say, there are few business metrics on which higher scores are always better scores. Higher scores on metrics such as customer satisfaction and product quality are not always indicative of higher profits. Customer satisfaction and product quality measures are primarily used as diagnostic metrics. Diagnostic metrics should be used to indicate the direction that changes should take to increase profits. Firms may find it more profitable to follow strategies that lower current customer satisfaction or that result in lower product quality.

The marketing ROI, also known as the ratio of marketing profit to the promotional effort, is a metric that has received a lot of attention as a metric for evaluating marketing performance. It is used in performance scorecards. MROI sounds like it should be a good candidate for a metric for which bigger is always better, and where bigger always indicates higher profits. "A higher MROI indicates your advertising is working (Livingston, 2010)." For many managers MROI is a goal and a higher MROI is a measure of higher productivity and higher profits. "As with ROS, a high value is desirable (Kotler and Keller 2010, p. A22)." Danaher and Rust (1994) argue that advertising is an investment and the goal is "to find the level of media spending which will maximize the return on investment." Many managers define MROI as a higher return on marketing costs or as a higher level of efficiency. Higher efficiency is often thought of as a positive performance indicator (Davis 2007, p. 242). Some research has shown a positive correlation between MROI and the firm's return on capital (Best, 2009, p. 50). The popular opinion seems to support the view that a higher MROI should always indicate a higher profitability. Unfortunately, higher MROI is not always an indicator of higher profits.

There are two possible reasons for the lack of a consistently positive relationship between MROI and profits. One is theoretical and the other is empirical. The popular reason for the lack of a consistently positive correlation between MROI and profits is measurement error. It is difficult to measure MROI. James Lenskold is a strong proponent of MROI as a positive measure of profitable performance. However, he provides eight reasons 
why higher MROI is not always associated with higher profitability (Lenskold 2003 p. 64). The eight reasons for the lack of a positive correlation are primarily errors in the measurement of MROI. They range from inappropriate conceptualization, faulty definition to inaccurate measurements. James Lenskold defines MROI as

MROI $=($ Gross Margin - Investment $) /$ Investment

where

Gross Margin $=$ net present value of revenue and expense income flows

Investment $=$ net present value of the sum of all at-risk marketing expenses.

Many marketers like to think of their marketing efforts having long-term benefits and feel that marketing expenses should be defined as marketing "investments" (Hawkin et al., 1987). There is no doubt that promotional expenditures and improvements in product quality can create assets such as brand equity and patents, however, the history of the expenditures needed to create the asset is not the market value of the finished investment.

It is the theoretical difficulties associated with MROI that have drawn relatively little attention and accurate interpretations of MROI are the focus of this paper. Farris et al. provide the most authoritative definition of MROI in their book on marketing metrics (2007, p. 320). They define MROI as

MROI $=($ revenue $)($ contribution margin $)-($ marketing cost $) /($ marketing cost $)$

where

Revenue $=$ Sales Revenue attributable to the marketing cost

MROI as a simple ratio indicating profitable performance has considerable appeal. However, Farris et al. provide a strong cautionary note about the use of MROI as a direct measure of profitability. "For most situations this metric is likely to be misleading (ibid, p. 320)." However, both Farris et. al. (ibid, p. 319) and Lenskold (2005, p. 55) suggest that the ratio of incremental changes in expenses to incremental changes in contribution is likely to be a superior measure of profitability.

Lenskold (ibid, p.318) defines the return on incremental marketing investment, ROIMI, as

$\mathrm{ROIMI}=((\mathrm{Y} 2-\mathrm{Y} 1)($ contribution margin $)-(\mathrm{X} 2-\mathrm{X} 1)) /(\mathrm{X} 2-\mathrm{X} 1)$.

where

$(\mathrm{Y} 2-\mathrm{Y} 1)=$ incremental change in sales revenue from period 1 to period 2

$(\mathrm{X} 2-\mathrm{X} 1)=$ incremental change in marketing spending from period 1 to 2

However, the manner in which the return on incremental marketing, ROIMI, should be applied and interpreted is not demonstrated or discussed.

In this paper, we define MROI as the net marketing contribution that results from any expenditure on promotional communications (e.g., advertising, direct mail, sales force calls, etc.). We do not include those marketing efforts and "investments" involved in improving product quality or pricing strategies as part of our definition of the marketing "investment". We restrict our definition of "return" to be net marketing contribution and exclude other popular measures such as prospects, leads, new accounts awareness levels, etc. That is to say, we follow the lead of Farris et al, (opt. cit.) to define Marketing Return on Investment to be

MROI $=(($ revenue $)($ profit margin $)-($ promotional expenses $)) /($ promotional expenses $)$ 
This paper demonstrates how MROI can be transformed from a measure of an average response to a promotion into a measure of marginal response. MROI can be useful managerial tool when it is cast as a measure of promotional elasticity. This paper builds on the above suggestions that MROI has dubious value as a measure of superior marketing performance and that it can be misleading to assume higher efficiency is always related to higher profit. The paper uses classic marketing theory to demonstrate that MROI is not always positively correlated with profitability. The goal of the paper is to demonstrate that the elasticity of MROI always indicates the direction that promotional activities should take in order to increase profits.

\section{ABUSING MARKETING ROI AS A MEASURE OF PROFITABLE PERFORMANCE}

Proponents of Marketing ROI as a measure of profitability argue that higher levels of MROI indicate firms with higher levels of profitability (Best, 2009, p. 58). The classic task of evaluation is to determine which of three firms has the most profitable performance. For example, when the simple income statements of three internet marketing firms (e.g., firm A, firm B, and firm C) with comparable markets, strategies, organization structures, and goals are evaluated, then the primary measure of desirable performance is net profit (Table 1).

Table 1: Profit as a Measure of Performance for Three Firms

\begin{tabular}{|l|c|c|c|}
\hline & Firm A & Firm B & Firm C \\
\hline Revenue & $\$ 25,909$ & $\$ 27,034$ & $\$ 28,984$ \\
\hline Marketing Expense & $\$ 10,600$ & $\$ 11,650$ & $\$ 13,600$ \\
\hline Net Profit & $\$ 15,309$ & $\$ 15,384$ & $\$ 15,384$ \\
\hline
\end{tabular}

Firms B and C have higher net profits than firm A and they are normally deemed to higher performance than firm A. On the basis of profit per period, Firm B and C are more desirable to investors than firm A. However, firm $\mathrm{B}$ and $\mathrm{C}$ are tied for profits and proponents of marketing ROI would argue that MROI should be given some weight in the evaluation of the firm's performance. The classic rational for MROI being included as a weighted measure of performance is that it will allow investors to break the tie in profit (Table 2) with a measure of superior efficiency. If promotional efficiency, MROI, were always associated with higher profits or higher potential profits, then higher MROI would be a good thing to include in a more balanced scorecard. However, we shall demonstrate that a higher MROI is not always correlated to higher profits. Higher profits can be associated with lower levels of efficiency.

Table 2: When a High MROI is in the Scorecard

\begin{tabular}{|l|c|c|c|}
\hline & Firm A & Firm B & Firm C \\
\hline Revenue & $\$ 25,909$ & $\$ 27,034$ & $\$ 28,984$ \\
\hline Marketing Expense & $\$ 10,600$ & $\$ 11,650$ & $\$ 13,600$ \\
\hline Net Profit & $\$ 15,309$ & $\$ 15,384$ & $\$ 15,384$ \\
\hline MROI & 1.44 & 1.32 & 1.13 \\
\hline
\end{tabular}

Firm A has a higher MROI than Firm C and Firm B, with MROI included in the scorecard. Firm A is deemed to have the best marketing performance of the three firms. However, there is a major difficulty in the calculation of the overall performance scores. Proponents of using MROI as a measure of profitable performance must determine the relative weights to assign to the MROI and to the profit. If too much weight is assigned to the MROI, then Firm A, which has the highest MROI but the lowest profit, will be deemed the firm with the highest marketing performance. When the goal is profit, then managers would never suggest that firm A, with the lowest dollar profit in Table 2, is the best choice for maximum profitable performance simply because it has the highest MROI. Firm A is more efficient but it is definitely not more profitable. The difficulty is that there is no general theory for the weight to be assigned to MROI that guarantees that MROI will not dominate the scorecards of firms competing for most profitable performance.

The authors experienced the difficulty in the selection of relative weights in the process of assigning grades to students who were playing a market simulation game. The grading allowed for weights to be given to MROI and net profit. However, problems arise when too many students where getting high grades when it was obvious to the instructors that their marketing expenditures were far too low to be profitable but their grades for profitable performance were compromised because they produced very high levels of marketing efficiency (i.e., MROI). The 
simulation the students played is built on actual industry data; and the negative correlation between high MROI and low profits was frustrating and not expected. The authors' searched for an explanation lead them directly to the classical theory that explains increases in sales due to increases in promotional effort.

The fundamental relationship between promotional expenditure and sales volume is one of diminishing returns (Figure 1). The classic equation is a power function of the form

$\mathrm{Q}=\mathrm{kA}^{\mathrm{a}}$

where

$\mathrm{Q}=$ the quantity sold due to promotion

$\mathrm{k}=$ scaling constant

$\mathrm{A}=$ the amount of money spent on promotion

$\mathrm{a}=$ the elastisticity of promotion $(0<\mathrm{a}<1)$

This relationship is discussed in Kotler's classic textbook on Marketing Decision Making (1971, p. 48) and more recently in Marketing Metrics by Paul Farris et. al. (2006, p. 319). Sales are always increasing as the amount of promotional effort is increasing but the incremental rate is decreasing. This type of power function was at the heart of the students' marketing simulation so that they would learn the lesson that over spending or under spending on promotion would generate less profit. The students were given the goal of finding the optimal level of promotion that would maximize profits. The instructors had wrongly assumed that higher promotional efficiency, MROI, was always associated with higher profits. However, when the students adopted the goal of increasing their promotional efficiency, MROI, then they would discover that higher levels of promotional efficiency could lead to lower profits.

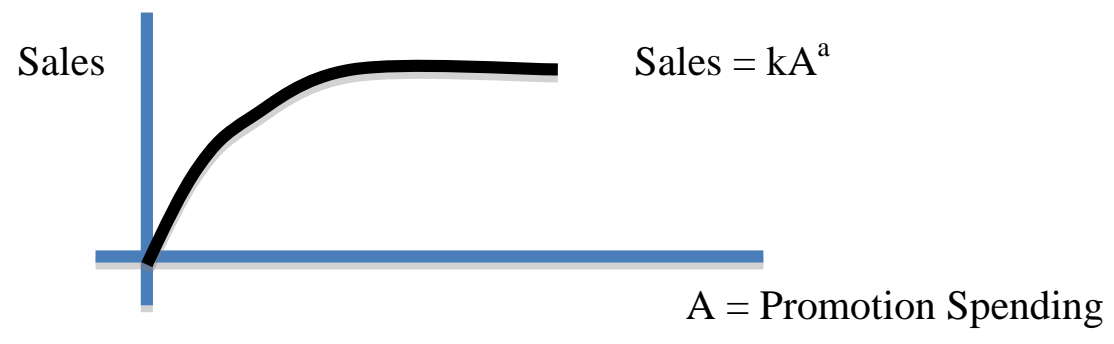

Figure 1: Sales as Function of Promotional Expenditures

The difficulty in finding a method for relying on MROI as a comprehensive indicator of profitability is primarily due to the fact that the general relationship between promotional effort and profit is quadratic in its nature. That is to say, the incremental changes in profit due to an incremental increase in promotional expenditure, first increases, reaches a maximum and then decreases (Figure 2).

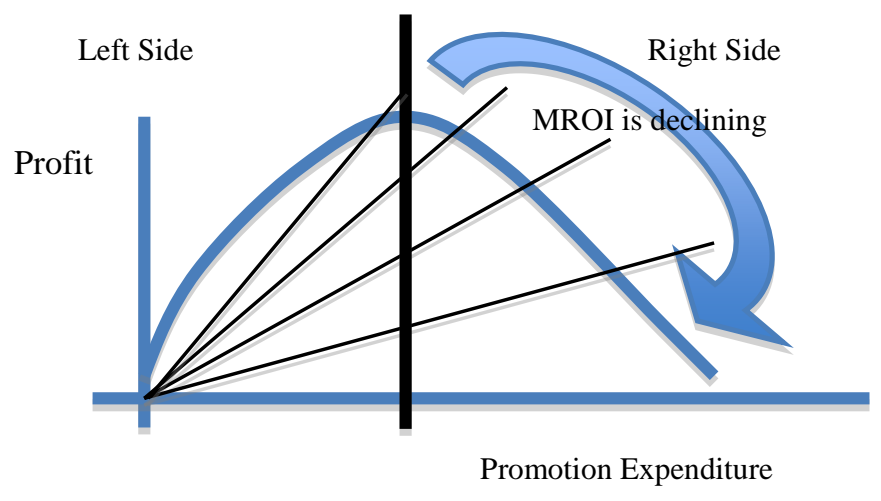

Figure 2: Relationship between Total Promotional Effort and Profit 
Conceptualizing the relationship between profit (i.e., net marketing contribution) and promotional expenditures as a quadratic function has been a mainstay of marketing theory for over 50 years (Dean 1951, p. 358). The procedure for finding the level of promotion that maximizes profit has been well established and involves the finding of the first derivative of the profit with respect to the promotion expenditure, dZ/dA. Calculating the promotion expense that maximizes profit, $\mathrm{A}^{*}$, involves setting the first derivative equal to zero and then solving for the promotion expense, $\mathrm{A}^{*}$. That is to say, if the profit function is

$\mathrm{Z}=\mathrm{MkA}^{\mathrm{a}}-\mathrm{A}$

where

$\mathrm{Z}=$ Profit after promotional expenses

$\mathrm{M}=$ Dollar Profit Margin per Unit Sold = Selling Price - Variable Cost

$\mathrm{k}=$ a scaling constant

$\mathrm{A}=$ Promotion expenditure

$\mathrm{a}=$ the promotion elasticity $(0<\mathrm{a}<1)$.

The first derivative is

$\mathrm{dZ} / \mathrm{dA}=\mathrm{aMkA}^{\mathrm{a}-1}-1$

(Equation 1)

and the promotion expenditure that maximizes profit is to set the first derivative with respect to promotion equal to zero and solve for $\mathrm{A}^{*}$ as follows

$\mathrm{A}^{*}=(\mathrm{aMk})^{1 /(\mathrm{a}-1)}$

\section{MROI OR EFFICIENCY AS A FUNCTION OF PROMOTION EXPENSE}

The marketing ROI is thought of as a measure of efficiency when it is presented as a simple ratio linking the promotional expenditures, A, to a profit, $\mathrm{Z}$.

$\mathrm{Z}=(\mathrm{Z} / \mathrm{A}) \times \mathrm{A}$

where

$\mathrm{Z}=$ Profit after promotion expenses

$\mathrm{Z} / \mathrm{A}=\mathrm{MROI}$

$\mathrm{A}=$ promotion expenditure

The ratio of profit to promotion, MROI, resembles the classic ratio of efficiency (i.e., Output/input). However, it is not immediately obvious or intuitive that the efficiency of the marketing effort as measured by MROI is always decreasing as the marketing effort is increasing. However, an inspection of the ratio

$\mathrm{MROI}=(\mathrm{Z} / \mathrm{A})=\left(\mathrm{MkA}^{\mathrm{a}}-\mathrm{A}\right) / \mathrm{A}=\mathrm{MkA}^{\mathrm{a}-1}-1$

(Equation 2)

shows it to be a downward sloping power function when the elasticity of promotion is between 0 and 1 (i.e., $0>a>1$ ). When the promotion expense, A, is very small, then the efficiency, MROI, is very large. The MROI or efficiency falls to zero as the promotional expenditure is increased to

$\mathrm{A}=(\mathrm{Mk})^{1 /(\mathrm{a}-1)}$

The decline in the MROI is easily demonstrated when a line is drawn from every point on the curve representing the profit to the origin in Figure 2 and the slope of the line is the ratio representing MROI. The slope of the MROI starts high when the promotion effort is low and the slope decreases to zero as the promotion effort is increased. 


\section{THE DECLINE IN MROI IMPLIES IT'S A POOR METRIC FOR EVALUATION}

The relationship between profit and MROI is positive on the right hand side of the function (Figure 2). That is to say, on the right hand side of the profit function any point of higher profit has a higher rate of MROI and, thus, marketing theory supports the hypothesis that profit increases as the MROI increases over this part of the function. However, on the left hand side of the function the relationship between MROI and profit is reversed and profits are increasing as the slope of the MROI is decreasing. When promotion levels are very small, then MROI is high (Figure 2) and as the promotional expenditures are increased from zero, then the MROI decreases as profits increase. Marketing theory tells us that the popular assumption that a higher level of efficiency, i.e. a higher MROI, is always positively correlated with higher profits is wrong. The theory predicts that firms will be observed operating on the left hand side of the function in Figure 2 and that higher profits will be associated with lower rates of efficiency or MROI. Marketing theory tells us that higher MROI should not be used as a surrogate measure of higher profitability. If managers use MROI as a goal, then increases in MROI can lead to lower profits.

\section{MAKING MROI INTO A DIAGNOSTIC METRIC}

The operational goal of this paper is to create a metric based on the sensitivity of the promotional efficiency (MROI) to changes in promotional expense, $\Delta \mathrm{A}$. The classic price elasticity of demand has the very useful characteristic that it is equal to -1 (i.e., $\% \Delta \mathrm{Q} / \% \Delta \mathrm{P}=-1$ ) when the price that maximizes revenue has been achieved. The goal of this paper is to demonstrate that the elasticity of MROI (i.e., $\% \Delta \mathrm{MROI} / \% \Delta \mathrm{A}$ ) has the same desirable characteristic of reaching -1 when the promotional expenditure that maximizes profit is reached. That is to say, an elasticity that indicates the point at which the optimal promotional expense is reached to achieve maximum profits.

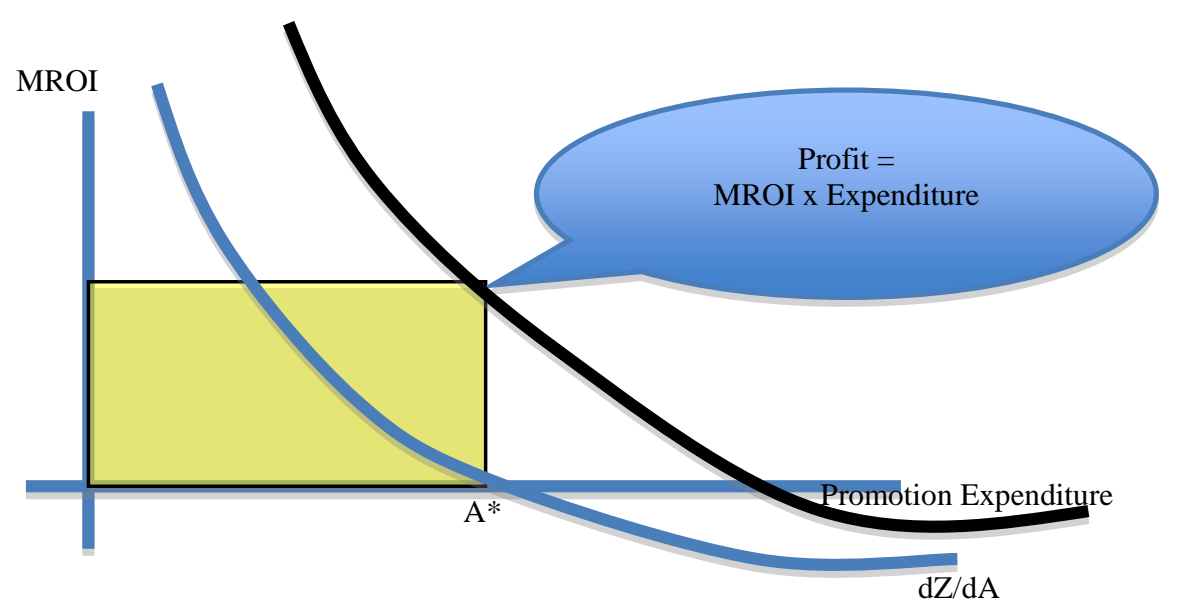

Figure 3: Relationship of Marketing Expenditure to Efficiency (MROI)

To convert MROI into a useful diagnostic, we exploit several characteristics of the relationship between profit and promotional expenditure. It is the continuous decline in MROI as promotion increases that allows MROI to be converted into a useful diagnostic. First, we note that the downward sloping relationship between MROI and marketing expense (Equation 2) allows us to calculate the profit at any point on that curve as the product of the promotion expense, A, and the MROI (Figure 3). We also note that the first derivative, dZ/dA, is a downward sloping power function that reaches zero with respect to promotional expense at the optimal level of promotion, $\mathrm{A}^{*}$ (Figure 3). That is to say, $\mathrm{A}^{*}$ is the level of promotion expense where the first derivative defines the area of maximum profit.

It also follows from the relationship between MROI and promotional expense in Figure 3, that the percentage change in promotion results in a predictable percentage change in MROI. We exploit the fact that dZ/dA is approximated by $\Delta \mathrm{Z} / \Delta \mathrm{A}$ and model the relationship between the changes in efficiency ( $\triangle \mathrm{MROI}$ ) and changes in promotional expense, $\Delta \mathrm{A}$, as 
$\Delta \mathrm{Z}=\mathrm{A}(\Delta \mathrm{MROI})+\mathrm{MROI}(\Delta \mathrm{A})$

(Equation 3)

$\mathrm{Z}_{2}-\mathrm{Z}_{1}=\mathrm{A}_{\min 1: 2}\left(\mathrm{MROI}_{2}-\mathrm{MROI}_{1}\right)+\mathrm{MROI}_{\min 1: 2}\left(\mathrm{~A}_{2}-\mathrm{A}_{1}\right)$

where

$\Delta \mathrm{Z}=\mathrm{Z}_{2}-\mathrm{Z}_{1}=$ the change in the gross profit from period 1 to period 2

$\mathrm{A}_{\min 1: 2}=$ the minimum of the two amounts spent on promotion in the two periods

MROI $_{\min 1: 2}=$ the minimum of the two MROI values in the two periods

$\mathrm{A}_{\min 1: 2}\left(\mathrm{MROI}_{2}-\mathrm{MROI}_{1}\right)=$ the impact on the change in profit due to the change in promotional efficiency

$\operatorname{MROI}_{\min 1: 2}\left(A_{2}-A_{1}\right)=$ the impact on the change in profit due to the change in promotional expenditure

The impact on profit due to the change in efficiency ( $\triangle \mathrm{MROI}$ ) is always in the opposite direction to the impact due to the change in promotional expense $(\Delta \mathrm{A})$. When the impact of one change is larger than the impact of the other change, then the amount of profit must change. For example, if the optimal amount of promotion, $A^{*}$, is spent, then the maximum profit of $Z^{*}$ is achieved and the optimal rate of efficiency, MROI*, is reached (Figure 4). When more money is spent on promotion than the optimum, $A_{2}>A^{*}$, then the extra promotion will generate more profits. The increase in profit is the amount measured as $\Delta \mathrm{Z}_{\mathrm{a}}=\mathrm{MROZ} *\left(\mathrm{~A}_{2}-\mathrm{A}^{*}\right)$. However, the higher level of promotion is also associated with a lower level of efficiency, $\mathrm{MROI}_{2}<\mathrm{MROI}^{*}$. The lower level of efficiency reduces the amount of profits. The reduction in profit due to the lower efficiency rating is measured as $\Delta \mathrm{Z}_{\mathrm{mroi}}=$ $\mathrm{A}^{*}\left(\mathrm{MROI}_{2}-\mathrm{MROI}^{*}\right)$. Since it is known that the maximum profit was at $\mathrm{A}^{*}$ and $\mathrm{MROI}^{*}$, then the net impact of the two changes is negative and the profit is lower. The new, higher level of promotion, $A_{2}$, is sub-optimal because it is associated with a higher level of inefficiency. The positive impact on profit due to the increase in promotion is more than offset by the negative impact of decreasing efficiency. We define the ratio of the impact due to the change in efficiency to the impact due to the change in promotion as the arc elasticity of promotional efficiency to promotion, (i.e., $\mathrm{E}_{\mathrm{ea}}=\% \Delta \mathrm{MROI} / \% \Delta \mathrm{A}$ ).

When the two impacts are equal, then the profit does not change and this occurs when changes are very small and the profit is at a maximum. When the profit is at a maximum, then the ratio of the two opposite and equal impacts is equal to -1 (i.e., $=\mathrm{E}_{\mathrm{ea}}=-1$ ). From a diagnostic point of view, if a firm has MROI elasticity between 0 and -1 , then promotional expenditure should be increased in order to increase profits. If the firm has a MROI elasticity smaller than -1 (i.e., $\mathrm{E}_{\mathrm{ea}}<-1$ ) then a reduction in promotional expenditure will increase profitability.

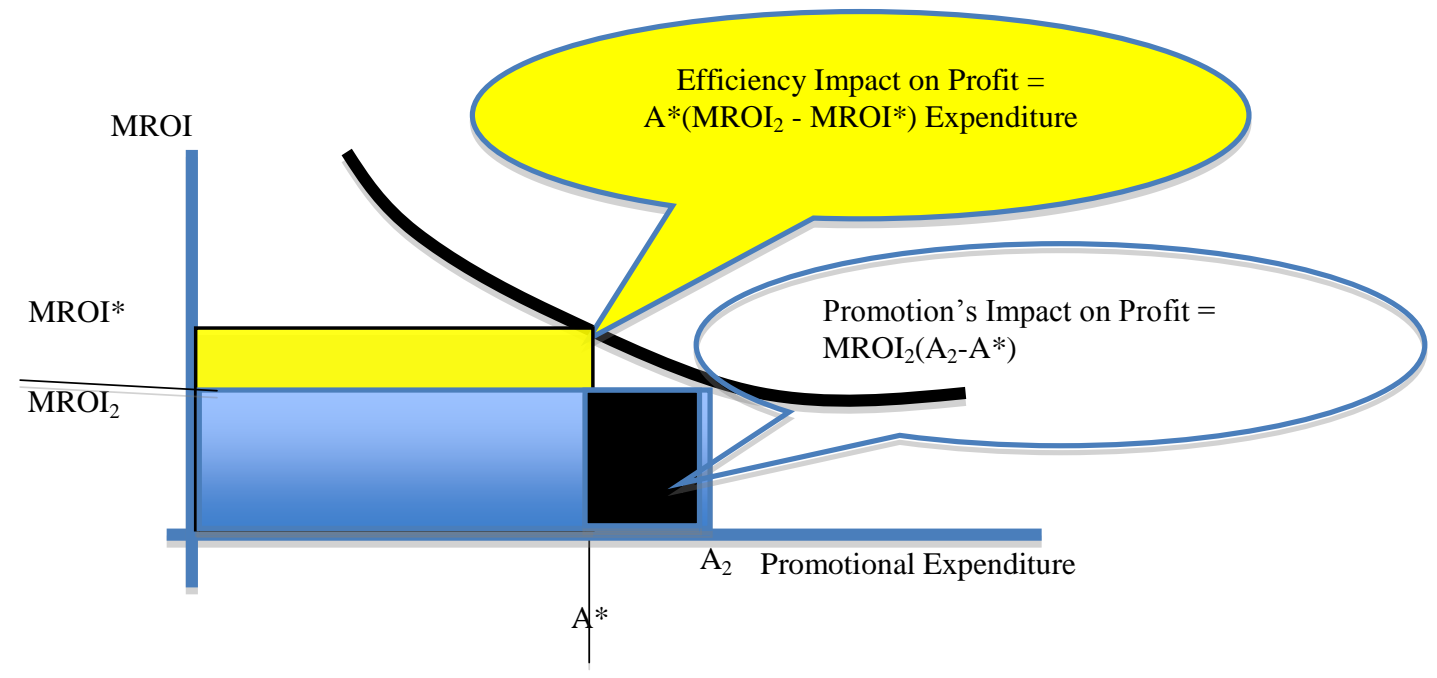

Figure 4: Relative Impact of Changes on the Change in Profit 


\section{MROI AS A DIAGNOSTIC TOOL}

In Table 4, the changes in firm A's profits increase, reach a maximum, then decrease as the marketing expenditure is increased from trial to trial. The sales revenue, and the quantity sold increase, as most managers expect, from trial to trial as the marketing effort increases. However, many practitioners do not expect the MROI to decrease as the promotional expenditure increases from trial to trial. That is to say, MROI continues to decrease while profit is increasing and decreasing.

Table 4: Firm A's Operating Statements over Time with Increased Marketing Expense

\begin{tabular}{|l|c|c|c|c|c|}
\hline & Trial 1 & Trial 2 & Trial 3 & Trial 4 & Trial 5 \\
\hline Revenue, R & $\$ 25,909$ & $\$ 27,034$ & $\$ 28,004$ & $\$ 28,984$ & $\$ 29,924$ \\
\hline Marketing Expense, A & $\$ 10,600$ & $\$ 11,650$ & $\$ 12,600$ & $\$ 13,600$ & $\$ 14,600$ \\
\hline Profit, Z & $\$ 15,309$ & $\$ 15,384$ & $\$ \mathbf{1 5 , 4 0 4}$ & $\$ 15,384$ & $\$ 15,324$ \\
\hline MROI & 1.44 & 1.32 & 1.22 & 1.13 & 1.05 \\
\hline \multirow{2}{*}{ Ratio of Changes from } & Period & Period & Period & Period & Period \\
& 0 to 1 & 1 to 2 & 2 to 3 & 3 to 4 & 4 to 5 \\
\hline Arc Elasticity of MROI, Eea & -0.91 & -0.95 & -0.98 & -1.02 & -1.06 \\
\hline
\end{tabular}

In the example (Table 4), the profit reaches a maximum in trial 3. The crucial insight is the observation that the elasticity of promotional efficiency moves from a value between 0 and -1 as the profits are increasing due to an increased marketing effort. The profit reaches a maximum when the MROI elasticity approaches -1 in trial 3 (Table 4). As greater and greater promotional effort is spent and the point of maximum profit is passed, then the MROI elasticity becomes more and more negative. The MROI elasticity is a sound diagnostic metric from a theoretical perspective. It indicates when an increase in promotional expenditure will increase or decrease the amount of profit being generated by the promotion.

\section{ASSUMPTIONS IMPACT ACCURATE MEASUREMENT}

There are assumptions about the elasticity of MROI that, like the elasticity of demand, that make it difficult to measure. For example, a key assumption is to have a minimal interaction between promotion and other elements of the marketing mix such as price and product quality. An accurate measure of MROI elasticity requires the researcher to control for changes in market demand caused by forces other than changes in promotion expenditure. However, the challenges of accurately measuring MROI exist regardless of how the metric is interpreted. The point of this paper is that changes in MROI should be interpreted correctly.

\section{USING ARC ELASTICITY RATHER THAN POINT ELASTICITY}

It is well known that large changes in the price have a major impact on the accuracy of price elasticity. Large changes in promotional expenditures also lead to greater inaccuracies in estimating the elasticity of the MROI at any single point. It is more useful to calculate the arc elasticity when using the changes from one period to the next. The process of calculating the arc elasticity of MROI begins with converting the changes in MROI ratio, $\triangle \mathrm{MROI}$, and changes in the promotional expense, $\Delta \mathrm{A}$, into changes measured in dollars of profit (Table 5). The magnitude of the two impacts can be compared directly when both are measured in terms of profit dollars. That is to say, the impact of the change in promotional expenditures, $\mathrm{I} \Delta \mathrm{A}$, on the change in profit, $\Delta \mathrm{Z}$, should be measured in dollars of profit. Similarly, the impact of the change in efficiency (i.e., I $\Delta \mathrm{MROI}$ ) on the change in profit, $\Delta \mathrm{Z}$, should be measured in dollars of profit.

Table 5: Calculating Average MROI Sensitivity between Periods 2 and 3

\begin{tabular}{|l|c|c|c|c|}
\hline & Period 2 & Period 3 & Change & Impact of Changes on Change in Profit \\
\hline Profit, Z & $\$ 15,384$ & $\$ 15,404$ & $\$ 20$ & -0.098 \\
\hline MROI & 1.3205 & 1.2225 & $\$ 11,650 \times(-0.098)=--\$ 1,141$ \\
\hline Marketing Expense, A & $\$ 11,650$ & $\$ 12,600$ & $\$ 950$ & $1.2225 \times(\$ 950)=\$ 1,161$ \\
\hline \multicolumn{4}{|c|}{ Average sensitivity of MROI between periods 2 and 3 } & $-1,141 / 1,161=-0.98$ \\
\hline
\end{tabular}


Equation 3 provides the means to measure the impacts of the changes on the change in profit. A key point in Equation 3 is in the application of the minimum of the two promotion expenditures for weighting the change in efficiency. Similarly the minimum value of the two efficiencies should be employed when calculating the impact due to the change in promotion expense. Promotion should be increased as long as the impact on profit gained from an increase in the promotion is larger than the negative impact of the profit lost due to lower efficiency, $\Delta$ MROI. The promotional expenditure should be reduced whenever the loss in profit due to the loss in efficiency is greater than the profit gained from an increase in marketing effort. The sum of the impact due to the change in MROI and the impact due to the change in marketing expenditure must equal the change in profit (e.g., $(\$ 1,161)+(-\$ 1,141)=$ $\$ 20)$. The ratio of the impact due to the change in MROI to the impact due to the change in marketing expenditure is the MROI elasticity (Table 5). The goal of marketing managers, seeking maximum profits, is to bring the ratio as close to -1 as possible.

\section{PRACTICAL PROBLEMS IN APPLICATION}

The many problems of measuring MROI and the amount of profit being generated by promotional expenditures have been down played in this paper to draw attention to the proper interpretation of MROI as a diagnostic metric. A discussion of the different elasticities for different types of promotion is beyond the scope of this paper.

\section{SUMMARY}

There is nothing in the marketing literature to suggest that marketing has abandoned the theory of concave functions for representing the relationship between profit and promotional efforts. Applying any of the functional forms suggested by Kotler (1971, p. 33) in our examples will generate the logical evidence that MROI continually decreases as profits rise and fall due to larger and larger promotion expenditures. If we assume concave functions, then the hypothesis that higher MROI is always positively correlated to higher profits is flawed and MROI is not a good metric of evaluating profitable performance.

Changes in marketing return on investment and marketing expenditures can be used to calculate an elasticity of MROI (i.e., the sensitivity of promotional efficiency to changes in promotional expenditure). The elasticity of promotional efficiency indicates if an increase or a decrease in promotional expense will increase net marketing profit. The manner in which to calculate and apply the elasticity of MROI is consistent with marketing theory. The mathematical logic for calculating the elasticity of MROI is parallel to the logic used for calculating price elasticity. The interpretation of the elasticity of promotional efficiency is identical to the interpretation of price elasticity of demand. If the elasticity is less than -1 (i.e., a larger negative number), then a decrease in price (alternatively promotional expense) will increase revenues (alternatively profits). If the elasticity is between 0 and 1 , then an increase in price (alternatively promotional expenditure) will increase the revenue (alternatively profit). If elasticity is equal to -1 , then the maximum revenue or alternatively the profit due to promotion has been achieved.

The measurement of price elasticity is useful enough for modern revenue management that the concept of demand elasticity is found in almost every introductory textbook on marketing principles. This new measurement of the MROI elasticity should be equally useful for managing profitable promotions. The authors are convinced that concept of using MROI as a measure of the sensitivity of changes in profit due to changes in promotional expenditures, will reduce the abuses of MROI as a surrogate measure of profitability. A better understanding about the nature of MROI (marketing efficiency) as a measure that declines continuously with a continuous climb in the level of promotional expenditure should help expunge the popular wisdom that higher MROI is always associated with high profits. Some empirical research may find support for the view that MROI is always associated with higher profits, but the hypothesis is flawed from a theoretical point of view.

\section{AUTHOR INFORMATION}

Theodore Mitchell, Ph.D., Managerial Sciences Department, College of Business Administration, University of Nevada, Reno, Nevada 89557-0206 USA. Email: Theodorem@unr.edu (Corresponding author) 
Howard Olsen, Ph.D., Managerial Sciences Department, College of Business Administration, University of Nevada, Reno, Nevada 89557-0206 USA. E-mail: howard@m3planning.com

\section{REFERENCES}

1. Best, Roger, (2009), Market Based Management, Fifth Edition, Pearson Education, Inc. Upper Saddle River, NJ.

2. Davis, John, (2007), Measuring Marketing: 103 Metrics Every Marketer Needs. John Wiley and Sons Pte, Ltd. Singapore.

3. Danaher, Peter J., and R.T. Rust, (1994) “Determining the Optimal Level of Media Spending," Journal of Advertising Research, January-February.

4. $\quad$ Farris, Paul W., Bendle, N.T., Pfeifer, P.E., Reibstein, D.J. (2006), Marketing Metrics: 50+ Metric Every Marketing Manager Should Master, Pearson Education, Inc. publishing as Wharton School Publishing, Upper Saddle River, NJ.

5. Kotler, Philip. (1971), Marketing Decision Making: A Model Building Approach, Holt, Rinehart and Winston, NY.

6. Lenskold, James, D., (2003), Marketing ROI: The Path to Campaign, Customer, and Corporate Profitability, McGraw-Hill, Published as American Marketing Association, New York, NY.

7. MacInnis, D. and Park, C.W., (2004), "Making the Most of Your Brand: Leveraging Brand Equity Through Branding Strategies". www.markingprofs.com, March. 